\title{
SOBRE DEMOCRATIZACIÓN \\ EDUCATIVA, LAICIDAD \\ CONSTITUCIONAL Y LOS \\ LINEAMIENTOS DE LA ENCÍCLICA $\ll$ FE Y \\ RAZÓN» EN MÉXICO
}

Virginia Aspe Armella

\section{RESUMEN}

ESTE TEXTO SE REFIERE AL LAICISMO CONSTITUCIONAL Y A LA EDUCACIÓN democrática en México a la luz de la Encíclica FidesetRatio».

La libertad de creencias no debeńa excluirla educación religiosa de las escuelas públicas; por el contranio, la libertad de creencias es la base para el reconocimiento entre las religiones y el Estado, la expresión de diferentes culturas y la nación.

La autora explora este problema mediante los principios de libertad, equidad y secularidad.

\section{ABSTRACT}

This text refers to the constitutional laicism and to the democratic education in Mexico from the "FidesetRatio" encyclical.

The freedom of creed should not exclude the religious education in the public schools; on the contrary, freedom of creeds is the basis of the recognition among the religions and the State, the expression of different cultures and the nation.

The author explores this issue through the principles of freedom, equity and secularity.

\section{INTRODUCCIÓN AL TEMA ${ }^{1}$}

Este texto tiene como finalidad señalar las bases de la democratización educativa en México. Nuestro escrito posee como hilo conductor la convicción de que por todas partes se realizan esfuerzos para promover más y más la obra educativa. Dicha labor se declara y afima en distintos documentos públicos como son la \eclaración 
de los derechos humanos universales de la ONU»y las garantías individuales de la «Constitución política de los Estados Unidos Mexicanos» En estos documentos se declaran los derechos privados de los hombres y las mujeres y, sobre todo, de los niños y niñas y de sus padres con respecto a la educación. La encíclica de Juan Pablo II, «Fides et Ratio», señala los límites y comesponsabilidades entre el conocimiento teológico y racional. Ella es pauta para la auténtica sabiduńa humana. Por ello, nos proponemos profundizar sobre la laicidad constitucional y la democratización educativa a la luz de sus lineamientos.

Los métodos de educación y de enseñanza se van perfeccionando con nuevas expeniencias, por esfuerzo de todos los hombres y mujeres para el cultivo de la verdad y la solidaridad. Para que el derecho a la educación sea pleno, responderá al fin propio del ser humano: la autorrealización compartida de su serpersonal mediante el óptimo desarrollo de sus capacidades, talentos y valores. Esta educación ha de ser equitativa en cuanto a oportunidades de desamollo y calidad; para ello, tomará en cuenta las diferencias de carácter, sexo, cultura, usos, costumbres y tradiciones.

Al mismo tiempo, la educación debe abrirse a relaciones fraternas con otros pueblos, a fin de fomentar en la tierra la verdadera paz.

La clave de una auténtica educación es la formación integral de la persona en orden a su plena realización y al bien de las sociedades de las que hombre y mujer son miembros, y en cuyas responsabilidades tomará parte cuando llegue a ser adulto. Esta ayuda - en especial a niños (as) y adolescentes- buscará tener en cuenta el progreso de las ciencias, sobre todo de la Psicología, la Pedagogía y la Didáctica, para desarrollar armónicamente las condiciones físicas, morales e intelectuales y fomentar, gradualmente, un sentido más perfecto de la responsabilidad en el recto y labonioso desarrollo de la vida y en la consecución de la verdadera libertad, superando los obstáculos con grandeza y constancia de espínitu.

La armonización o equilibrio de estas condiciones, incluyen des- 
de una positiva y prudente educación sexual hasta la preparación para la participación en la vida social, de tal modo que, bien instruidos, con los medios necesarios y oportunos, los educandos participen activamente en los diversos grupos sociales, estén dispuestos (as) para el diálogo con los y las demás, y presten su colaboración gustosa al bien común.

Los y las niñas y adolescentes tienen el derecho a que se les fomente el aprecio - con recta conciencia de su parte- de los valores morales. Por esta apreciación, poseen el derecho a prestarsu adhesión personal a los valores que les parezcan más adecuados. También, a que se les estimule a conocery amara Dios, si es que ellos y sus padres y madres lo desean.

Los padres y madres tienen el derecho inalienable y la obligación de educar a sus hijos (as) favoreciendo una formación íntegra, personal y social. Sin embargo, este deber de los padres y las madres necesita de la ayuda de otros; es por esto que ellos eligen a quienes cooperarán con ellos en esta tarea educativa.

En realidad, los padres y las madres requieren de toda la sociedad para lograrel fin educativo ya que el ser humano es libre y social por naturaleza. Esto implica que aprende, se desamolla y crece con y por los demás, y no sólo por sí mismo. La tarea educativa es eminentemente social a la vez que personal, pues es por la libertad que cada uno forja su personalidad y carácter mediante la adquisición de hábitos y virtudes.

La reforma educativa en México precisa reflexionar sobre el principio de la libertad - indispensable en la democratización educativa - y el principio de laicidad constitucional - imprescindible en la educación mexicana- , ambos principios requieren operar armónicamente.

El principio de libertad religiosa se señala en nuestra Constitución como una garantía individual al proclamar la libertad absoluta de los mexicanos. La importancia del principio de libertad religiosa estriba en que las creencias de las personas se insertan y manifiestan 
en su vida privada y social. En cuanto que las creencias se exterionzan socialmente en la cultura de un pueblo, éstas han de ser tomadas en cuenta por el Estado.

La sociedad civily la educación son afectadas por el fenómeno religioso. Porello, es menester que el Estado reconozca y regule dicho hecho social para promoverel bien común sin detrimento de los valores nacionales.

\section{EDUCACIÓN Y SOCIEDAD CIVIL}

Gracias a la vertiente social de la educación, podemos afimar que la sociedad civil tiene ciertos derechos y obligaciones educativas. La sociedad civil es responsable de disponer todo lo requenido para el bien común temporal de la educación.

Las obligaciones de la sociedad civil respecto a la educación de niñosy adolescentes son variadas, las más importantes son²:

- Tutelarlos derechos y obligaciones de los padres y las madres y de todos los demás que intervienen en la educación y colaborar con ellos(as).

- Completar la obra de la educación según el principio de subisidaridad: si no es suficiente el esfuerzo de los padres o madresy de otras sociedades, atendiendo a los deseos de éstos, la sociedad civil ha de coadyuvar con los que menos tienen.

- Crear escuelas e institutos propios según lo exija el bien común. Entre todos los medios de educación, la escuela tiene especial importancia.

La misión de la escuela consiste en:

Cultivar con cuidado las facultades intelectuales.

Desarmollarla capacidad del recto juicio.

Introducir el patrimonio de la cultura conquistado por las generaciones pasadas.

Promoverel sentido de los valores.

Prepararpara la vida profesional.

Fomentar el trato amistoso entre los alumnos de diversa índole y 
condición.

Contribuir a la mutua comprensión, promoviendo el respeto, la equidad y la tolerancia.

Durante el sexenio pasado y el que actualmente transcurre, se han dado reformas y adiciones constitucionales relevantes para la educación en México.

Estas refomas implicaron modificaciones en el tema de educación ${ }^{3}$, cambios en cuanto a credosy relaciones entre el Estado y las iglesiast, así como adiciones en tomo al concepto de cultura de nuestra Nación ${ }^{5}$. Por su relevancia, profundizaremos en ellos. Textos como la Declaración de los derechos humanos de la ONU» la «onstitución política de los Estados Unidos Mexicanos», el «Nuevo Derecho eclesiástico del Estado»y la encíclica Fides et Ratio»son indispensables en esta tarea. La reforma religiosa que vino a ampliar la garantía individual constitucional de libertad, manifiesta que todo individuo mexicano tiene plena libertad a profesar el credo que desee.

La libertad de credo dio lugar a otra reforma en la Constitución: las relaciones entre las iglesias y el Estado. Volveremos con amplitud sobre este punto más adelante.

Una adición a la Constitución que nos parece relevante en esta investigación compete a la acción cultural y educativa en México: La nación mexicana tieneuna composición pluricultural ${ }^{6}$.

El texto vino a perfeccionar las garantías individuales de libertad, educación y cultura contempladas en la Constitución.

Pareciera que estos cambios han sido adecuados al auténtico sentido de nuestra Carta Magna que proclama, desde su inicio, las garantías individuales acordes con la \eclaración de los derechos humanos universales de la ONU».

La legislación vigente en tomo a la libertad de credo y relaciones entre las iglesias y el Estado amplió la garantía primera de libertad absoluta de todos los mexicanos al tomar en cuenta los siguientes principios: 
- Principio de libertad religiosa: no cabe coacción alguna a quien profese un credo ni a quien desee ser educado en él.

- Principio de separación del poder religioso y temporal: no implica una disociación absoluta y contempla las relaciones entre ambos poderes. Está fundamentada en el principio de libertad pues es la misma persona quien tiene derechos ćivicos y religiosos.

- Principio de laicidad: el Estado no interviene en asociaciones religiosas ni en las iglesias y a la inversa, las asociaciones religiosas y las iglesias no interfieren en los asuntos del Estado.

- Principio de igualdad: se exige un trato equitativo a todas las iglesias y religiones. El Estado no puede privilegiar iglesia ni religión alguna.

Como puede observarse, los principios sobre credo e iglesias que contempla la legislación vigente son adecuados a los derechos humanos fundamentales. La reforma constitucional de 1992 fue acertada en sus principios, aunque todavía exige la ampliación de ciertos mecanismos para llevarla a plenitud.

Las reformas a la Constitución de 1992, en los artículos 3ㅜㅜ 24으, $27^{\circ}$ y $130^{\circ}$, recuperaron este principio esencial a la libertad de los mexicanos: la libertad de credo. En consecuencia, se dio la apertura a las relaciones entre las iglesias y el Estado. Sin embargo, el principio de laicidad todavía no es comprendido plenamente porla sociedad.

Para entendercon profundidad la laicidad constitucional parece oportuno señalara creyentes y no creyentes los lineamientos que la Encíclica Fe y Razón precisa:

Para la religión católica la verdad no es patrimonio de la cristiandad:

Tanto para orientecomo para occidenteesposibledistinguirun camino que, a lolargo delossiglos, ha llevado a la humanidad a encontrarseprogresivamente con la verdad y a confrontarse con ella. Una simplemirada a la historia antigua muestra con claridad cómoen dis tintaspartesdela tierra, marcadaspor culturas diferentes, brotan al mismotiempolaspreguntasquecaracterizan el recorridodela existencia humana: ¿quién soy?¿Dedóndevengoya dóndevoy?:Por quéexiste 
el mal?¿Quéhay despuésdeesta vida?Estasmismaspreguntaslasencontramosen losescritossagradosdeIsrael, pero aparecen también en los Veda; lasencontramosen losescritosdeConfucioyLao-Tseyen la predicación delos Tirthankana ydeBuda; asimismo seencuentran en los poemasdeHomeroyen lastragediasdeEurípidesy Sófocles, asícomoen lostratadosfilosóficosdePlatón y Aristóteles. Son preguntasquetienen su origen común en la necesidad desentido quedesdesiemprealudía el corazón del hombre: dela respuesta quesedéa talespreguntas, en efecto, dependela orientación quesedéa la existencia?

El texto parte de la convicción de que el ser humano es capaz de alcanzar la verdad porvariados caminosy de que todos estos progresos sobre la verdad pueden hacercada vez más humana la existencia: Lasrespuestasquesehan ido dando seenmarcan en un horizonteque poneen evidencia la complementariedad delasdiferentesculturasen las queviveel hombre ${ }^{\beta}$. La Encíclica sostiene que: Cada puebloposeeuna sabiduna oniginaria yautóctona que, comoauténtica riqueza delasculturas, tiendea madurarseya expresarseen formaspuramentefilosóficas. Para la Encíclica, la prueba de esto se encuentra en que diversas legislaciones nacionales e intemacionales inspiran sus postulados en tales razonamientos humanos.

Más allá de las diferencias culturales y de los distintos caminos para la verdad, existe un patrimonio común de la humanidad constante en su historia del pensamiento. La Iglesia reconoce y aprecia el esfuerzo que porla sola razón hace cada vez más digna la existencia personal y social; y de la Filosofía-ciencia porla luz de la razón natural, el camino para conocer verdades fundamentales relativas a la existencia del hombre ${ }^{9}$.

La defensa que hace la Encíclica es a la posibilidad humana de alcanzar la verdad. No se trata de argumentar exclusivamente, desde la fe, con verdades reveladas sino de aceptar la posibilidad de encontrary argumentar racionalmente la verdad sin caer en relativismos absolutos en donde todo se tome opinable. 
Existe una diferencia clara entre las verdades de fe y de razón. En las primeras, es Dios quien habla a las criaturas; en las segundas, es el hombre quien, con su razón, penetra sobre las verdades fundamentales. Estas dos dimensiones, sin embargo, no son excluyentes.

Ambos caminos son legítimos para alcanzarla verdad aunque se distingan por su método y objeto. El método de las verdades reveladas se funda en el testimonio de Diosy con la ayuda sobrenatural de la gracia; el método de la Filosofía y de las ciencias parte de la percepción de los sentidosy la experiencia, y se funda en la luz de la sola inteligencia. En ambos casos, se accede a la verdad aunque la iluminación de la fe por la gracia del Espínitu Santo revela la plenitud de la verdad ${ }^{10}$.

Esta revelación divina se inserta en el tiempo y en la historia por lo que ambas verdades, aunque con método y objeto distinto, se entrelazan y coadyuvan en la dinámica humana. Razón y fe no son dimensiones contranias aunque cada una tiene su propio espacio de realización ${ }^{11}$. Un modo como Dios se manifiesta es a través de la naturaleza, por lo que el saber científico que investiga la estructura del mundo, siempre será para la Iglesia un saber legítimo y de gran $\operatorname{dignidad}^{12}$.

El imperativo que la Encíclica encuentra en todo ser humano es la obligación moral debuscarla verdad y deseguirla una vez conoci$\mathrm{da}^{13}$. Se puededefinir, pues, al hombre como aquel quebusca la ver$\operatorname{dad}^{14}$, pero la Encíclica precisa que existen diversas formas de verdad y distintos modos de buscarla ${ }^{15}$ :

Cuando la laicidad constitucional se entiende como mera separación de las verdades religio sas y científicas se cae en el emor de concebir a la verdad exclusivamente desde una dimensión. El laicismo, mal entendido, deviene en una visión cientificista de la realidad que no deja espacio para otros modos de descifrar e interpretaral hombre y al mundo. La mentalidad positivista, por una mala interpretación del laicismo modemo, no ha dejado espacio para verdades trascendentes y morales. El laicismo mal entendido, ciema toda posibilidad 
que la razón se abra a la trascendencia. Implica una consideración autónoma incapaz de abrirse hacia lo otro, distinto de sí mismo. Una razón tal sólo puede producirse desde sí misma, se hace instrumental, sirve a fines utilitaristas o para dominaru onientarse al propio placer. Lejos de alcanzar laverdad que se encuentra en la apertura a lo diverso, la razón autónoma cae en un nihilismo sin sentido.

El verdadero sentido de la laicidad constitucional debe encontrarse en la necesidad humana de conocimiento natural, verdadera y coherente respecto del hombre y del mundo, y la necesidad de articular el conocimiento racional de forma conceptual y argumentativa ${ }^{16}$. La laicidad no es sólo separación de las iglesias y del Estado porlas diferencias de principios, métodos y objetos, sino una prueba más de que el conocimiento humano implica orden y argumentaciones racionales diversas. Las formas racionales de argumentación junídicay política son distintas a las argumentaciones de las verdades de fe. Con la laicidad se separan las argumentaciones racionales de las sobrenaturales, pero se reconoce a ambas como posibles al ser humano. Por ello, el sentido adecuado de laicidad no excluye argumentaciones y razonamientos de fe en aquellos mexicanos que deseen hacerlas; ello atentańa contra el principio de libertad y en consecuencia se estańa en contra de una democratización educativa en la cual, la tolerancia y el pluralismo son esenciales por la libertad.

La importancia del laicismo constitucional radica en la necesidad de aportar argumentos racionales para el desamollo de las culturas y la formación cívica y ética. Fomenta puntos de unión entre distintas religiones y con aquellos que carecen de fe. La Encíclica promueve que la filosofía cristiana argumenta a la luz de la razón y según lasreglas de la razón - aunque guiada siempre porla inteligencia que le viene de la palabra de Dios- para desamollar una reflexión comprensible y sensata a quienes no perciben la verdad de la Revelación. Con ello, se facilita la solución de renovación no sólo a los creyentes sino a la humanidad entera, impulsando las verdades fundamentales no sólo 
desde la fe, sino desde una antropología de la persona, una Ética y una Ontología ${ }^{17}$. Dicho texto, en consecuencia, es decisivo para la sana comprensión del sentido de laicidad en México.

El origen histónico en el cambio del témino laicidad se encuentra en la Asamblea General de las Naciones Unidas de 1948. En dicha asamblea se aprobó la libertad religiosa de los individuos. En adelante, el artículo 18 de la Declaración Universal de Derechos Humanos ha sostenido que:

Toda persona tienederecho a la libertad depensamiento, deconocimientoy dereligión; estederecho incluyela libertad decambiardereligión o decrencia, individualycolectiva, tantoen públicocomoen privado, porla enseñanza, la práctica, el cultoyla observancia.

Con dicho texto la ONU proclama la libertad religiosa de modo universal; sin embargo, habnían de ser las legislaciones nacionales de los Estados miembros quienes incorporanian dicha declaración en sus constituciones. México integra en su Constitución la libertad religiosa hasta 44 años después de esta Declaración ${ }^{18}$.

Un texto clave del Concilio Vaticano II esclarece esta declaración. La encíclica \ignitatis Humanae»sostiene que un derecho humano de todo individuo es la libertad religiosa ya que Dios puede serconocido no sólo por los creyentes mediante datos revelados sino por todos los hombres gracias a la razón natural. El texto de la Encíclica - sostiene Alberto Pacheco, el especialista en Derecho Eclesiástico Estatal Mexicano - refiere a un doble aspecto: negativo, según el cual no se debe coaccionara nadie para obrar contra su conciencia; y positivo, según el cual cada ser humano tiene el derecho a actuarconforme a su conciencia y esa actuación debe ser en público o en privado, al serpública, puede asociarse con otros para ejercer su libertad.

El texto de la DignitatisHumanaesconsidera clave que cada hombre y cada mujer obren conforme a su conciencia, puesesun deber naturalquetienetodo hombre, por ser racionaly estar dotado devoluntad libre, debuscarla verdad y deobrar conformea ella ${ }^{19}$. 
Es responsabilidad del Estado mexicano el vigilarque esta inmunidad de coacción sea hecha realidad en la sociedad mediante disposiciones legislativas, administrativas y judiciales.

El artículo 24 de nuestra Carta Magna sostiene que Todo hombrees libredeprofesarla creencia religiosa quemásleagrade. El artículo $3^{0} \mathrm{en}$ la fracción 1, proclama también la libertad de creencias, también el artículo 24 habla de la libertad para profesar creencias. En realidad, desde el artículo $1^{1}$ de la Constitución se declara la libertad absoluta de los mexicanosy con ello podemos decirque el derecho a la libertad religiosa es una garantía constitucional individual.

Veamos en qué consiste cada uno de los principios sobre libertad de credo y reconocimiento de las distintas religiones en nuestra Constitución:

- Sobre el principio de libertad religiosa: podemos decir que se basa en la garantía individual de libertad. Dicha proclama se constituye al principio en un derecho civil.

- Sobre el principio de igualdad: este principio no quiere decir que todas las religiones sean iguales en su verdad, sino que el Estado les da un trato igual, es decir, que todas las iglesias tienen ante la ley, los mismos derechos y obligaciones.

- Sobre el principio de laicidad: la palabra laicidad es un término que ha evolucionado a lo largo de su historia. En su inicio, dicho término liberal e ilustrado tras la revolución francesa, tenía una connotación antimeligiosa y anticlerical.

Para el especialista Alberto Pacheco, la prueba de dicha mala interpretación del término está en que en los países protestantes no fue utilizado en sus legislaciones (prueba de que la mala interpretación surgió desde países mayoritariamente católicos).

Conforme la reflexión sobre Derechos Humanos profundizó en el siglo XX, el término laicismo fue evolucionado por un sentido más adecuado de laicidad. Esta última palabra significaba, con mejorprecisión, el uso conveniente del término. Porello, en la exposi- 


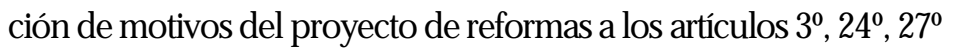
fracción II y $130^{\circ}$ de la Constitución, presentada por el Partido Revolucionario Institucional, se sostuvo que ${ }^{20}$ :

El laicismo no essinónimo deintolerancia y anticlericalismo, con ello se rescata el uso adecuado del término «aicidad»en donde se reconoce que el Estado es incompetente ante la fe porque no es su terreno ni campo de acción ya que la fe y las religiones no están en la naturaleza del Estado, en cuanto tal Estado.

El Estado establece relación con las iglesias, pues las creencias y religiones son realidades y hechos sociales, y en cuanto manifestaciones cívicas han de ser reguladas porél. Ello no obsta para que el Estado confunda su campo de acción con las iglesias, pues mira a las religiones sólo como hechos sociales sin carga ideológica deninguna especie, en palabras de Pacheco, y porello la función del Estado debe serlaica. Al Estado como autoridad rectora de la Nación, le compete salvaguardar el principio de libertad religiosa e intervenir cuando éste sea violado en aspectos políticos, económicos, etcétera.

Los artículos 3ํㅡ $22^{\circ}$ de la Constitución, sostienen que el Estado Mexicano es laico y que su intervención se limita a:

La observancia de las leyes en dicha matenia.

La conservación del orden público en este campo.

La conservación de la moral pública.

La tutela de los derechos de terceros.

La regulación de los actos de culto público.

La protección de la salud, seguridad y tranquilidad del bien común en este orden.

El principio de separación de lasiglesias y el Estado es indispensable para regular los derechos y obligaciones de las iglesiasy su relación con el Estado en cuanto asociaciones civiles, ya que ambos promueven la realización de los derechos elementales del serhumano.

El peligro de no proclamar constitucionalmente el principio de separación entre el Estado y las iglesias consistió en la confusión de 
funciones - algo que ocumó durante el inicio del México independiente y con la negación de las funciones religiosas durante la segunda mitad del siglo XIX en México.

Hemos de tener en cuenta las bondades del principio constitucional de separación de las iglesias y el Estado mexicano. La laicidad del Estado mexicano es adecuada con los lineamientos de \&ey razón»pues no cae en la trampa de declararse un Estado ateo que implicaría la negación de la religión y de Dios; ello supondńa tomar una postura sobre verdades que no le competen. El principio de separación de lasiglesiasy el Estado no fue promulgado en aras de la tolerancia, como frecuentemente se interpreta, sino en aras de la libertad de conciencia y pensamiento. Éste es el fondo adecuado en que la laicidad constitucional ha de moverse y que coincide con las tesis de la encíclica «idesetRatio».

Porúltimo, veamos el principio de igualdad que estableció la reforma a los artículos $3^{\circ}, 24^{\circ}, 27^{\circ}$ y $130^{\circ}$ de la Constitución en torno al problema de la libertad religiosa.

\section{SOBRE EL PRINCIPIO CONSTITUCIONAL DE} IGUALDAD ENTRE LOS MEXICANOS

\section{ANTECEDENTES}

El principio de igualdad no puede entenderse, en lo concreto, de modo unívoco y homogéneo. La Constitución mexicana proclama la igualdad entre todos los mexicanos sostienida ante la ley. Un junista español - Amadeo De Fuenmayor- explica el sentido de igualdad ante la ley»que proclaman las constituciones actuales: La igualdad antela ley trata deevitar, sobretodo, quelosadministradossean tratadosde modoarbitrario... la igualdad no esmásqueuna idea abstracta quese traduceporla generalidad dela ley, peroquenopuedeimpedirnumerosasdistincionesentrelaspersonassometidasa la ley ${ }^{21}$. Es decir, en un primer sentido, el principio constitucional de igualdad exige una aplicación igual a Derecho.

En un segundo sentido, dicho principio entraña el rechazo a toda 
desigualdadjurídica material, esdecir, la prohibición dediferenciacionessin fundamentoracional22.

Para que el principio de igualdad constitucional sea entendido plenamente, es menesteracudira un tercer sentido del término que esla igualdad proporcional entrelosdestinatariosdel principio ${ }^{23}$.

En esta perspectiva, la igualdad se entiende porla dignidad y valor de todo ser humano. Es indispensable considerarla igualdad - de modo proporcional - pues de lo contrario, se cae en injusticias.

Bajo esta óptica, el Derecho constitucional tiene que tomar en cuenta que no cabe libertad ni igualdad absolutas entre los mexicanos porque toda ley implica prohibición de arbitrio, y porque cada ser humano es libre y oniginal.

S el ordenamientojurídico pretendiesealcanzaruna igualdad absoluta, habría dellegaralabsurdo deigualara todoslossujetos, bajo todos losaspectosposibleseinimaginables, yen tal caso seanularía a si mismo. Tendría querenunciar a cualquier disciplina entreloshombres, ya que no podrían existir relacionesdiversas; o bien habría detomaren consideración todosloselementosylascaracteństicasdelosparticulares, para acomodarla disciplina correspondientea lasdiferenciasnaturales, con lo quevendría a negarseel conceptomismo deigualdad ${ }^{24}$.

Congruente con este problema, el Tribunal Europeo de Derechos Humanos sostuvo que la desigualdad no constituye necesariamente una discriminación: La igualdad essólo violada si la desigualdad está desprovista deuna justificación objetiva y razonable, yla existencia de dicha justificación debeapreciarseen relación a la finalidady efectosde la medida considerada, debiendo darseuna relación razonabledeproporcionalidad entrelosmediosempleadosyla finalidad perseguida ${ }^{25}$.

Para efecto del tema que nos ocupa, el principio de igualdad constitucional nos parece que fue el motor de la inclusión del principio de laicidad en las constituciones modemas. En el caso de México, pensamos que el deseo expreso de los constituyentes de 1917 en laicidad constitucional, se debió a la necesidad deigualar la educación en México $^{26}$. La exclusión de cualquier tipo de credo unificańa 
las políticas educativas suprimiendo las diferencias religiosas a través de una ciencia positiva y fáctica. Sin embargo, esta proclama del principio de igualdad concebida con univocidad teminológica, atentó, paradójicamente, contra el principio de libertad, pues los padres ya no podían ser libres de escogeruna escuela que, a la vez, permitiera la libre formación religiosa de sus hijos.

Un caso significativo de cómo la igualdad absoluta atenta contra la libertad y la justicia de los sujetos si no se imparte proporcionalmente, es el caso de la Circular de la Asamblea General del Consejo de Estado Francés, de 1989. En dicho texto se recomienda a todas las escuelas francesas que se impida a los alumnos vestiro usarcualquier tipo de signo religioso, por considerarse proselitista.

En aquel entonces un grupo de niños árabes de religión musulmana acudía a la escuela portando pañoletas rojas en la cabeza - algo que su religión imponía-. Ante la negativa de los padres de evitar en sus hijos este tipo de signos, los directivos de la escuela acudieron a las autoridades educativas estatales. El caso llegó hasta el Consejo de Estado Francés quien emitió una circularpara todas las escuelas, señalando que, en aras de la laicidad constitucional, los niños debían serobligados a retirarsus pañoletas. La opinión pública protestó por esta violación a la libertad de creencias. Y con ello se levantó un debate público ${ }^{27}$. Este caso, aunque europeo, no es ajeno a la circunstancia mexicana. En México, los Testigos de Jehová no participan en las escuelas públicas ni privadas de la formación cívica ni de las ceremonias patrias. Ello lleva a los profesores a la paradoja de excluir a dichos alumnos de la escuela o a aceptar que no participen en asignaturas y ceremonias obligatorias para los educandos.

Sobre este problema conviene aclarar que el principio de igualdad que proclama el Estado en materia religiosa no significa que todas las religiones sean igualmente verdaderas, pues al Estado no le compete hacer juicio sobre verdades religiosas, ya que lo conducina a la paradoja de tenerun problema que no puede resolverseparado de la colaboración eclesiástica. 
El principio de igualdad puede emar al interpretarla igualdad ente la ley como igualdad ante la verdad sobrenatural, cayendo en juicios religiosos, algo que no puede extraerse de un documento estatal.

Quien puede emitirjuicios valorativos sobre verdades religiosas es la sociedad civil; es en ella donde se insertan las creencias. Por ello, es indispensable que el Estado tome en cuenta las convicciones del pueblo a pesardeno interveniren ellas. La importancia en la comprensión de los principios constitucionales analizados radica en la adecuada delimitación del poderestatal y las verdades religiosas y sobrenaturales.

Persisten todavía grandes prejuicios y equívocos en torno a las relaciones entre iglesias y Estado. En ocasiones, se confunden los valores éticos con los religiosos, así como en la educación privada de escuelas católicas se mezclan a veces las verdades sobrenaturales con la falta de sustento científico. Por ello, en un esfuerzo por esclarecer más estos principios, proponemos:

1. Señalar la coincidencia de los documentos estatales y religiosos. 2. Señalar las coincidencias y diferencias de las verdades de razón y fe.

Con ello creemos contribuir al esclarecimiento de muchos prejuicios mexicanos en torno a la libertad religiosa y responsabilidad estatal. Así, los mexicanos podrán regular adecuadamente los problemas surgidos en tomo a educación estatal y libertad de credo. En primer lugar, cabe señalar que los principios sobre credo e iglesias que contempla la legislación vigente en México son adecuados a los derechos fundamentales del ser humano.

La reforma constitucional de 1992 fue acertada en sus principios (aunque exige todavía la ampliación de ciertas regulaciones para llevarla a plenitud). El principio de igualdad religiosa debe ser precisado para evitar confusiones de juicios valorativos del Estado sobre distintas religiones. Es indispensable para la tarea educativa de los mexicanos, que se profundice más sobre estos principiosy que se fundamente dicha reflexión desde la delimitación y conciliación de los conceptos de «Razón y fe». 
Para ampliary continuaradecuadamente esta reforma educativa consideramos indispensable delimitar con precisión los siguientes problemas:

1. La laicidad en México no sólo es un principio constitucional que influye en la educación sino - consideramos nosotros - una exigencia histónico-cultural para los mexicanos. Promoverexplícitamente la información sobre el auténtico sentido de laicidad es tarea urgente en la formación educativa. La laicidad educativa no es antimeligiosa ni debe serlo: exige que la tarea educativay escolar se sustente con argumentaciones científicas, éticasy cívicas - es decir, humanas, congruentes con la razón y la naturaleza- exige también que se informe a los educandos de lo común y de lo distinto en los temas de razón y fe.

2. Es indispensable que este nuevo sexenio continúe con las reformas educativas en curso de la SEP; aunque habnía que contemplarsi el modo y los mecanismos actuales son adecuados.

3. Es importante que la tarea educativa sea plural, abierta, para vivir los valores democráticos de pluralismo, tolerancia y equidad. Sin embargo, estos valores han de ejercerse a partirde un marco común, evitando la anarquía y los relativismos. Por plurales y tolerantes que sean en el terreno educativo, las institucionesy el magisterio deben cumplir con ciertos parámetros de calidad y coherencia científica, ética y cívica. La tolerancia no implica aceptar cualquier cosa: por ejemplo, no puede aceptarse la legislación del aborto si la vida es el primerderecho constitucional y la base de los derechos de la humanidad. Tampoco podemos admitir acciones contra la ecología en aras de la tolerancia.

4. La ampliación de la reforma educativa en México ha de centrarse en el desamollo personal y cívico de los ciudadanos. Este desamollo implica necesariamente la adquisición de hábitos, aptitudes, valores y virtudes. La educación es tarea formativa, no sólo informativa. La clave de la educación radica en saber usar la información veraz adquinda, en saber adaptarla a las necesidades concretas de las personas y de su comunidad, en hacerla vida» 
5. Una renovación educativa centrará su atención en la libertad del educando y ha de seracorde a su dignidad de persona. 6. Todo proyecto educativo fomentará la apertura a otras culturasy pueblos. Al mismo tiempo toda tarea educativa deberá seramaigada y construida desde la realidad nacional. En ella, existen múltiples diferencias variables por lo que un proyecto educativo nacional ha de contemplar la pluriculturalidad de México, sus diversas necesidades según las regiones y comunidades. No cabe imitar o trasladar modelos educativos extranjeros sin una profunda transformación de los mismos respecto a la realidad mexicana.

7. Los proyectos educativos de cualquieríndole requieren estar abiertos y actualizados a los avances modemos del progreso, a la vez que asumir la tradición cultural del país. Por otro lado requieren sustento científico, humanista e interdisciplinario con un enfoque social. 8. Una educación integral exige incorporar el tema de Diosy de las religiones. Éste es un tema recumente en toda la histonia de la humanidad. Tanto para las culturas de oniente como para las de occidente, la explicación mítica y religiosa ha sido un modo de descifrar el cosmos. El maestro y la maestra incorporarán la explicación científca del mundo, pero ello no obsta para que el o la maestra deje a un lado argumentos sobrenaturales respecto de ciertos temas.

9. Un problema indispensable en la educación democrática estriba en la delimitación de las funciones de la SEP. La SEP debe escuchar e incluira las distintas fuerzas de la Nación para que - sin prejuicios y de viva voz - actualice las necesidades educativas de México. Pensamos que el papel de la SEP es, como toda función del Estado, regulador. Ésta, habnía de marcar lineamientos generales de calidad y raigambre mexicana, a la vez que de la humanidad en su conjunto y fomentarque sean las escuelas y los maestros quienes adapten estas generalidades a la realidad concreta. La SEP todavía se muestra intervencionista en ciertas cuestiones que, a nuestro parecer, no le competen.

10. En México, cualquierrenovación educativa ha de comenzarpor 
la paga de mejores salanios al magisterio. El magisterio, sin temor a equivocarnos, es la labor más digna de los mexicanos. Los maestros son el enlace entre la educación materna y paterna y la sociedad civil. Ellos tienen, en sus manos, la responsabilidad de los valores éticos y cívicos. Si no cuentan con tiempo suficiente para preparar sus lecciones e informarse de los nuevos avances de las ciencias, así como de las nuevas manifestaciones de la cultura, difícilmente formarán y apoyarán personalmente a sus alumnos y alumnas. En la apertura plural y democrática de la educación, los y las maestras son el eje y motor de su dinamismo. Son los maestros quienes han de seleccionar los textos adecuados a las circunstancias concretas de sus alumnos, entre la amplia gama de aquéllos reconocidos por la SEP. Es responsabilidad de la SEP verificar la calidad de los textos utilizados por escuelas públicas y privadas. Si se libera indiscriminadamente la selección de libros de texto de educación básica y media supenior en México actualmente, no se darán las condiciones para mejorarla educación en el país.

\section{SOBRE EDUCACIÓN Y CREDOS}

En México actualmente más del 90\% de los ciudadanos profesa un credo de inspiración cristiana, incluimos con ello sectas y distintas religiones. La mayor parte de los mexicanos son católicos. En consecuencia, aunque una educación democrática ha de contemplar también el credo de las minońas, pensamos que es indispensable atender a la Declaración Cristiana de la Juventud en el Concilio Vaticano II para comprenderel tipo de mentalidad y obligaciones de este sector mayoritano de la población. Este punto nos parece indispensable para regular adecuadamente la laicidad de la educación en México con base en el principio de equidad religiosa. No podemos excluirninguna religión para formularun proyecto educativo presente en nuestro país, pues atentaníamos contra la libertad. Por ello, antes de preguntarnos por los principios educativos del cristianismo, conviene incluir el Código de Ética de las Distintas Religiones en México. 
Dicho código no sólo sustenta los principios éticos comunes a toda religión sino que garantiza el laicismo constitucional, pues formula sus criterios con argumentos humanos y no mediante cuestiones reveladas. Este documento está avalado por los representantes de las iglesias en México y nos parece indispensable en una cultura educativa para evitarinequidades e intolerancia.

A continuación presentamos dicha declaración:

CÓDIGO DE ÉTICA PARA LAS RELACIONES ENTRE LAS RELIGIONES

CONSEJO INTERRELIGIOSO DE MÉXICO ARTÍCULO $1^{\circ}$

Sereconocen comofundamentaleslosderechosdelaspersonasproclamadosen la Declaración Universal delosDerechosHumanosdela ONUy en la Constitución Política delosEstadosUnidosMexicanos.

\section{ARTÍCULO $2^{\underline{0}}$}

Antela sociedadyla conciencia universal, todoslossereshumanosnacen libreseigualesen dignidady derechos.

\section{ARTÍCULO 3ำ}

Toda persona tienetodoslosderechosy libertadesproclamadosen los artículosantecedentesyen esteCódigo deÉtica, sin distinción alguna de confesión o creencia religiosa, raza, color, sexo, origen, nacionalidad, tradición, opinión política ocualesquiera otrascondiciones.

\section{ARTÍCULO $4^{\circ}$}

Toda persona eslibredeprofesarla religión queestédeacuerdocon los dictadosdesu conciencia; asimismo, tienederecho a la libertad depensamientoya cambiardereligión ocrenciassin coaccionesdeninguna índole. 


\section{ARTÍCULO 5o}

Ninguna persona será atacada, ridiculizada, ni difamada porla forma deexpresarsu feosuscreencias, ya sea individualmenteocomomiembro deuna institución ogruporeligioso.

\section{ARTÍCULO 6음}

Ninguna persona será obligada a pertenecer a una institución ogrupo religioso determinado, nia renunciara profesaralguna creencia.

\section{ARTÍCULO 7ํㅜ}

Cuandouna persona deseesepararsedeuna institución ogrupo religioso, no será obligada a explicar losmotivosdeconciencia desu decisón.

\section{ARTÍCULO 8음}

Todaslaspersonastienen el derecho deasociarselibrementepara la celebración desusceremoniasreligiosas, respetando la convivencia pacífica entrelasdiversasexpresionesdela fe.

\section{ARTÍCULO 9o}

Toda persona ocomunidad religiosa, seabstendrá deatacar, ridiculizar ocalumniar lostextosquesean consideradoscomo fundamentodesu fe porcada comunidad oinstitución religiosa.

\section{ARTÍCULO $10^{\circ}$}

Losgruposo institucionesreligiosas, osusmiembrosen particular, al refenirse, demanera oral omediantela edición detextos, a lascreencias yexpresionesdela fedeotraspersonasoinstitucionesreligiosas, lo harán bajo el signo demutuo respeto.

\section{ARTÍCULO 11ำ}

Al hacer proselitismo orecibirsolicitudesdeingreso, lasinstitucioneso gruposreligiososdeberán explicarclara yampliamenteal solicitante, los derechosy obligacionesqueseadquieren al formarpartedeellos. 


\section{ARTÍCULO $12^{\circ}$}

Losgnuposo insitucionesreligiosas, al extenderinvitacionesa reuniones, conferencias, conciertosoactosdecualquieríndole, expresarán claramente elnombredela comunidadoasociación queorganiza el evento.

\section{ARTÍCULO 13o}

Lospadreso tutorestienen el derechoy la libertad inalienablesdeescogerla educación y la enseñanza religiosa para sushijossin quemedie coacciónalguna.

\section{ARTÍCULO $14^{\circ}$}

Lasescuelasy centrosdeenseñanza sostenidos, patrocinadoso dirigidos por institucioneso comunidadesreligiosas, osusmiembrosen particular, deberán respetarla libertad dedecisión delospadreso tutoresen lo relativo a la educación religiosa desushijos.

\section{ARTÍCULO 15음}

Nadieserá excluidoni discriminadodela educación básica ymedia por motivosdecrencia religiosa, políitica, raza, nacionalidad, condición socialniorigen delospadreso tutores.

\section{ARTÍCULO 16음}

Toda persona, al llegar a la edad núbil definida por la ley, tieneel derecho decontraermatrimoniolibrementeysin restricción alguna por motivosderaza, nacionalidad, origen ni creencia religiosa.

\section{ARTÍCULO 17ำ}

Alcontraermatrimonio, ninguna persona debesercoaccionada ni obligada a rompersuspropiosvínculosfamiliaresni socialesa causa desu pertenencia o separación deuna comunidad o institución religiosa, 0 porprofesaralguna crencia. 


\section{ARTÍCULO $18^{\circ}$}

Nadieserá coaccionadoni obligadoa rompersuspropiosvínculosfamiliaresni socialesa causa desu pertenencia o separación deuna comunidad oinstitución religiosa, o porprofesaralguna creencia.

\section{ARTÍCULO 19음}

Ematrimonioyla familia son componentesfundamentalesdela sociedad, porlocual, ambasinstitucionesdeben serincondicionalmenteprotegidaspor el Estado, lascomunidadeso gruposreligiososyla sociedad misma.

\section{ARTÍCULO 20ㅜㅡㅁ}

Ninguna persona será discriminada, perseguida, privada desu libertad ni desusbienes, desterrada ni exiliada a causa dela profesión de suscreenciasreligiosasni desu membresía en una institución ogrupo religioso.

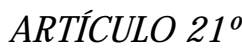

Laspersonasqueprofesan diferentescrencias, aś comolasinstituciones religiosas, trabajarán con mutuorespeto, en armonía para promoverla fraternidad, el cuidado del medioambiente, el bienestaryla paz delos individuos, lascomunidadeso gruposreligiososyla sociedad misma.

\section{ARTÍCULO 22ํㅜㅇ}

Losgruposeinstitucionesreligiosasestablecerán entreś diálogoscon el objetivo deconocersemejordemanera mutua, teniendo comometa la eliminación delosprejuiciosdesusmiembroshacia otrasformasdeexpresión defeypráctica religiosas ${ }^{28}$.

Nos parece indispensable insistir en las relaciones entre las iglesias y el Estado para una recta renovación educativa en México, por las siguientes razones:

- En México existe una tradición católica que se refleja en el credo, 
la conducta y mentalidad de los mexicanos. En ocasiones este credo se ha reducido a un clericalismo ambiguo que confunde la autoridad y las formas con el contenido de la fe. De ello deriva el problema de no vivir la adecuada laicidad que proclama la Constitución Política de los Estados Unidos Mexicanos. En otros momentos, el Estado ha confundido estas dimensiones, llegando incluso a perseguir, confiscarbienes o matar ciudadanos por pertenecer a una religión o practicar algún culto. Los mexicanos hemos de defender la libertad religiosa y la separación entre las iglesias y el Estado. Además, hemos de vivir genuinamente la tolerancia ante los distintos credos. La fe supone un acto de voluntad y nadie puede sercoaccionado para practicar un credo distinto al que, por su libertad, ha elegido. El principio de equidad para las distintas religiones es un principio basado en el derecho inalienable a la libertad.

- En México existe el problema de la supresión, en algunas religiones, de la educación cívica. En este renglón se requieren acuerdos junídicos concretos, por ejemplo, en México quienes son Testigos de Jehová, no hacen honores a la bandera y no desean asistir a la matena de Formación Cívica y Ética.

- Existen sectasy asociaciones religiosas que no garantizan los derechos fundamentales del ser humano ni la regulación de asociaciones, sectas y nuevas formas de religiosidad. Estos grupos han de comprobar su adecuación a los Derechos Humanos de la ONU y a las garantías individuales y sociales de la Constitución.

- Existe todavía el problema de la confusión de plano temporal y religioso.

- Se requieren acuerdos junídicos sobre la participación civil de las iglesias, su limitación y funciones.

- Existe también un problema de inequidad en los medios de comunicación. Se requieren regulaciones en tomo a la influencia equitativa de los medios y la necesidad de que éstos cubran en sus espacios esta problemática.

- Se requieren regulaciones sobre la injerencia ilegítima de autorida- 
des eclesiásticas en asuntos de Estado y a la inversa: de autoridades públicas en asuntos religiosos.

\section{SOBRE LA COMPATIBILIDAD DE DECLARACIONES HUMANAS, POLÍTICAS Y RELIGIOSAS}

La Declaración de la Educación Cristiana de la Juventud (Concilio Vaticano II., Pablo VI, 1965) se apega a la Declaración Universal de los Derechos Humanos de la ONU y a las tesis que suscribimos en este artículo. En la declaración mencionada, se manifiestan los principios reguladores con el Estado. Dado que la mayor parte de la población mexicana es católica nos parece indispensable que se conozca este texto para prevenir confusiones en torno al papel de la Iglesia y el Estado. En dicho documento:

- Se proclama el Derecho Universal a la Educación.

- Se proclama el derecho de los individuos a recibir una educación cristiana, si se es cristiano, en los valores naturales contenidos en la consideración integral del hombre, pues el cristiano - sostiene el texto - al haber sido redimido por Cristo, contribuye al bien de toda sociedad.

El texto sostiene el derecho de comunicar a los creyentes la vida de Cristo y de ayudarles con atención constante para que logren la plenitud de esta vida. Sin embargo, ésta no es la única función educativa de la Iglesia cristiana, pues, en tanto que sociedad humana, es capaz de educaren el terreno de la ciencia, el arte y los valores.

La Iglesia aprecia muchoybusca penetrardesu espíritu ydignificar también losdemásmediosquepertenecen al común patrimonio dela humanidady contribuyen grandementea cultivarlasalmasya formar a loshombres, como son losmediosdecomunicación social, losmúltiples gruposculturalesyeducativos, lasasociacionesdejóvenesy, sobretodo, lasescuelas ${ }^{29}$.

En el rango educativo, la escuela cristiana promoverá el desarrollo 
de las facultades intelectuales del ser humano, una conciencia moral recta, valores adecuados a la humanidad en su conjunto, excelencia profesional, cultural, cívica y religiosa apoyada en los padres y maestros.

Dicha educación escolartendrá en cuenta el pluralismo de la sociedad modema, la libertad religiosa y los nuevos avances pedagógicosy científicos del progreso contemporáneo.

Contemplará las diferencias de sexo para llevar a cabo el principio de equidad de género. Estos puntos tiene que impartirlos con una atención personal digna.

Los padres cristianos tienen la obligación de sostener las escuelas católicas y colaborar con ellas ${ }^{30}$.

\section{SOBRE LA SEPARACIÓN Y CONCILIACIÓN DE LAS VERDADES DE FE RAZÓN}

La reforma constitucional de 1992 sobre libertad religiosa es de importancia decisiva en la educación mexicana. Porsu relevancia, presentamos los lineamientos de la encíclica Fe y razón»en cuanto a la separación y conciliación de las verdades racionales y sobrenaturales en la sociedad civil. Ello contribuye a la formación de una auténtica educación laica en México.

El Estado mexicano, al ser laico, promoverá una adecuada separación entre las verdades que éste promulga y promueve - que son del orden racional - y las verdades que garantiza a las iglesias - que son del orden de la fe.

Atendera una adecuada comprensión de la separación entre fe y razón implica, sin embargo, aceptar las dimensiones en que este tipo de verdades coinciden (pues es en la misma persona y sociedad en donde se insertan ambas verdades). Consideramos que la encíclica de Juan Pablo II, Fe y razón»esclarece las diferencias y coincidencias entre nuevas verdades. Las señalamos a continuación:

La realidad se manifiesta al ser humano de distintas maneras, pues en tanto que la realidad es análoga, la verdad se da en distintos órde- 
nes ${ }^{31}$. La humanidad ha progresado en la búsqueda de la sabiduría desde que existe. Culturas diferentes y religiones distintas han participado en el progreso de la verdad ya que ésta es una necesidad común a todo ser humano ${ }^{32}$.

El ser humano tiene muchos medios para progresaren la verdad: revelados, políticos, sociales, científicosy éticos ${ }^{33}$.

Los postulados de las legislaciones nacionales e intemacionales que regulan actualmente la vida social manifiestan estas verdades fundamentales del ser humano y contribuyen al progreso social. Ellas han añadido significaciones diversas a la existencia, aportando conocimientos universales; pues existe una capacidad natural de especulación humana que ayuda a encontrar nuevas formas de conocimiento riguroso, congruencia lógica y saber sistemático.

La Encíclica sostiene que la labor de los jerarcas eclesiásticos radica en testimoniar las verdades de fe y en colaborar con las verdades de razón natural.

Al ser la Iglesia la depositaria de las verdades de fe, se considera depositaria de un mensaje que tiene su origen en Dios mismo. En este campo sostiene que las verdades de fe no provienen de la propia especulación humana. Porello el Concilio Vaticano II puso de relieve el carácter sobrenatural de la revelación de Dios. Sin embargo la Iglesia sostiene que:

Hayun dobleorden deconocimiento, distintonosólo porsu principio sino también porsu objeto; por su principio, primeramente, porqueen uno conocemosporrazón natural, y en otroporfedivina; porsu objeto también porqueapartedeaquellascosasquela razón puedealcanzar, se nosproponen para creermisteriosescondidosen Diosdelosque, deno habersidodebidamenterevelados, no sepudiera tenernoticia ${ }^{34}$.

En consecuencia, podemos decir que:

La fe se funda en el testimonio de Dios con la ayuda sobrenatural de la gracia y que la fe es de un orden distinto al conocimiento natural porque ${ }^{35}$ : 
- Está iluminada y guiada por el Espíritu.

- Su mensaje es de salvación sobrenatural.

- Implica la plenitud de la gracia y de la verdad.

- Se origina en la revelación divina.

- El medio para su consecución es Jesucristo.

En esta revelación, Dios invisible ${ }^{36}$, movido de amor, habla a los hombres como amigos ${ }^{37}$, trata con ellos para invitarlos y recibirlos en su compañía.

Sin embargo, la revelación de Dios se inserta en el tiempo y en la historia ${ }^{38}$. La historia es el lugar donde podemos constatar la acción de Dios en la humanidad. Dicha verdad se abre a todo hombre y a toda mujer en este mundo y está llena de misterio ${ }^{39}$.

Pero Dios se da a conocera los hombres también de otra manera: por medio de la razón natural. Las ciencias naturales y otras reflexiones humanas son también una forma de sabidunía ${ }^{40}$. Con este tipo de verdades el ser humano está en condiciones de conocerla estructura del mundoyla actividad deloselementos, losciclosdel año, la posición delosastros, la naturaleza delosanimalesy losinstintos delas fieras. Más aún, razonando por la naturaleza se puede llegara Dios. Las verdades de las ciencias naturales, de la filosofía y de la reflexión racional natural:

-Se apoyan en la percepción de los sentidos.

-Se sustentan en la experiencia.

-Son a la luz de la sola inteligencia.

Por esa reflexión, cabe decirque la razón rebasa porsí misma los límites naturales, ${ }^{41}$ conoce las causas, es decir, manifiesta la sabiduńa divina ${ }^{42}$ de tal manera que Pablo de Tarso pudo enfrentaral paganismo griego y aceptar el culto al «dios desconocido» adaptando susargumentacionesal propiomododeserpagano, superandolocontingenteyllegando a loinfinito ${ }^{43}$.

Esta capacidad legítima de verdad se ha manifestado también como 
una sabiduría práctica. La defensa de la libertad y los valores verdaderos son alcanzables a todo no creyente que busca la verdad pues la verdad se manifiesta de múltiples formas. Éstas son:

- Las verdades que se apoyan en evidencias inmediatas (cotidianas).

- Las verdades que se apoyan en las evidencias confirmadas expenimentalmente (científicas).

- Las verdades capaces de especulación intelectual (filosóficos).

- Las verdades últimasy del principio porrevelación (religiosas).

Estas distintas dimensiones de la verdad dan lugar a verdades en las tradiciones, lenguajes, culturas, comunicaciones, creencias y verdades interpersonales. Estas últimas son las verdades más ricas.

En consecuencia, la Encíclica acepta distintas verdades y establece los vínculos entre fe y razón una vez que ha establecido la legítima separación entre ambas. Ella sostiene que desde los libros sapienciales de la Sagrada Escritura, se aceptan no sólo las verdades de fe, sino las verdades de civilizaciones y culturas varias, por ejemplo, las verdades de Egipto y Mesopotamia. Esto se debe a que essabio todo aquel queama ybusca la verdad ${ }^{4}$.

Para que la razón humana investigue la verdad, en legítima dedicación del mundo y del hombre desde el plano natural, se requiere lo siguiente:

- Reconocer que el conocimiento humano no tiene descanso.

- Tener conciencia que dicho camino no se puede recorrer con el orgullo de quien piensa que todo es fruto de la conciencia personal. - Admitir la trascendencia sobrenatural de Dios y su amorprovidente.

En consecuencia, la verdad de fe no se contrapone a las de razón aunque son diferentes. Dios se da a conocerpor medio de la naturaleza y su conocimiento es posible desde la sola reflexión natural.

Las relaciones entre fe y razón implican una distinción específica de órdenes. Este tema es tan antiguo como el inicio del cristianismo. El cristianismo se apoyó en el conocimiento natural, en la voz de la 
conciencia humanay en el conocimiento filosófico pagano ${ }^{45}$.

Con ello se inició un diálogo fecundo entre fe y razón ${ }^{46}$. En conclusión, el cristianismo afirma el derecho universal a la verdad, más allá de un credo o de no teneno ${ }^{47}$. Pues todos los hombres son iguales ante Dios. La verdad no es patrimonio de elite alguna.

La pregunta de Tertuliano: «Qué tienen en común Atenas y Jerusalén?) es una pregunta que ha de hacerse todo mexicano. La academia y la Iglesia, el poder temporal y sobrenatural pueden coexistir sin confundir sus funciones, cuando se reconocen los aspectos positivos y los limites entre ambos ${ }^{48}$.

El poder temporal, sin embargo, no estállamado a expresarjuicio alguno sobre los contenidos de la fe, pues es incapaz de hacerlo al no serpropio de su función y método ${ }^{49}$.

Para México, lo novedoso de esta Encíclica radica en establecer un nuevo numbo a la razón: el punto capital de ella radica en conciliarla secularidad del mundo con las exigencias del Evangelio sin confundir los campos ${ }^{50}$.

Fe y razón, en consecuencia, son formas de sabiduría complementaria. El poder temporal puede coexistir con el poder sobrenatural sin confundir los principios, caminos y fines específicos. Su recta colaboración hará de México una Nación plena, con un Estado laico capaz de garantizar la auténtica libertad religiosa.

\section{CONCLUSIÓN}

La laicidad de la Constitución mexicana, las recomendaciones del Código de Ética para las Distintas Religiones, la Declaración sobre la Educación Cristiana de la Juventud, y los lineamientos de la encíclica «e y razón»no se contraponen.

La laicidad constitucional promueve que la educación escolary universitaria se organice de tal manera que cada disciplina se cultive y desamolle según sus principios, sus propios métodos y la propia libertad de la investigación científica; esto está contemplado también en los otros documentos citados. En última instancia, es menesterrecal- 
cara la sociedad cristiana mexicana que la verdad, el bien y la belleza son valores de la cultura reflejados temporalmente en la naturaleza, en el ejercicio cívico de las personas; el temeno natural de educación de los padres que promueve la Iglesia, ha de sustentarse con argumentos racionalesy éticos, y no con argumentaciones religiosas; ello no obsta para que dicho desarrollo humano contribuya decisivamente en el plan de aquellos que profesan el credo cristiano.

Es indispensable mantenerel principio de laicidad que profesa la Constitución Política de los Estados Unidos Mexicanos en la reforma de 1992. Este principio tiene como eje el principio de libertad.

La libertad educativa posee como fundamento la Declaración de los Derechos Humanos de la ONU y las garantías constitucionales de México. Ninguna educación religiosa en México puede estarpor encima de estos derechos fundamentales ni obstaculizarlos. En consecuencia, las iglesias y el Estado pueden funcionar legítimamente con la sociedad civil. Si se mantiene el principio auténtico de laicidad que promueve la reforma de 1992. Como el Estado es autoridad rectora de la Nación, toca a él regularlos acuerdos pertinentes entre las distintas iglesias. Esto ha de ser llevado a cabo junto con la sociedad civil pues, en la forma republicana del gobierno de México, el Estado representa losinteresesy valores de los mexicanos. 


\section{REFERENCIAS BIBLIOGRÁFICAS}

${ }^{1}$ Agradezco a la doctora Dora Sierra sus aportaciones bibliográficas y el diálogo fecundo sobre el tema.

${ }^{2}$ Tomamos los lineamientos de la Declaración cristiana dela juventud, adaptándolos a las necesidades de México.

${ }^{3}$ Artículo 4º de la Constitución. Creado en 1974 y añadido en 1992 ${ }^{4}$ Artículo $3^{\circ}, 24^{\circ}, 27^{\circ}$ y $130^{\circ}$.

${ }^{5}$ Reforma educativa con base en la pluniculturalidad de México, realizada durante el sexenio de Emesto Zedillo y del secretario de Educación Miguel Limón Rojas. Diciembre 18 de 1997.

${ }^{6}$ Dicha adición rebasa un concepto unívoco, homogéneo, de cultura en México que tuvo como principio el mestizaje; reconoce distintas mentalidades, usos y costumbres en los mexicanos que repercutirán en adelante en la democratización de la educación.

${ }^{7}$ Introducción a la encíclica Fey razón., CI., p.1.

${ }^{8}$ F. etR, 3.

${ }^{9} \mathrm{~F}$. etR, 5 .

${ }^{10} \mathrm{~F}$. et R, 9 .

${ }^{11} \mathrm{~F}$. et $\mathrm{R}, 17$.

${ }^{12} \mathrm{~F}$. et R, 19.

${ }^{13} \mathrm{~F}$. et $\mathrm{R}, 25$.

${ }^{14} \mathrm{~F}$. et $\mathrm{R}, 28$.

${ }^{15} \mathrm{~F}$. et $\mathrm{R}, 30$.

${ }^{16} \mathrm{~F}$. et $\mathrm{R}, 66$.

${ }^{17} \mathrm{~F}$. et R, 104.

${ }^{18}$ Cfr. PACHECO, Alberto., Temas deDerecho Eclesiástico Mexicano., Ed. Centenario., México., 1993., p.30. El texto citado es fundamental a lo largo de toda nuestra investigación. «a obra del doctor Alberto Pacheco es un análisis juńdico de las recientes leyes del Derecho Eclesiástico Mexicano. Dicho análisis se hace a la luz de los Derechos del Hombre» José Luis Soberanes Femández. Prólogo a la obra citada.

${ }^{19}$ Texto de Alberto Pacheco que además es apoyado porel jurista 
Ramón Sánchez Medal en La libertad religiosa en la nueva legislación mexicana., IMDOSOC., México., 1992.

${ }^{20}$ PACHECO, Alberto., Op.cit., p.39.

${ }^{21}$ DE FUENMAYOR, Amadeo., «Alcance del principio constitucional de igualdad»en Revista Persona y Derecho., Suplemento Humana IURA., Vol.2., Pamplona., 1992., p.248-251.

${ }^{22}$ Op.cit., p.25.

${ }^{23}$ Dicho sentido de igualdad se origina en la filosofía de Aristóteles y es rescatado por Leibholz para la doctrina científica y la jurisprudencia constitucional de Alemania y otros países.

${ }^{24}$ ROSSANO., Lúguaglianza giuridica nell'ordenamento costituzionale., Nápoli., 1966., p.256.

${ }^{25}$ Tomado de DE FUENMAYOR, Amadeo., Op.cit., p.260.

${ }^{26}$ Un texto indispensable para comprender este problema en su origen es El movimiento educativo en México., Dirección de Talleres Gráficos., México., 1922. En dicho texto se incluye la discusión del proyecto de ley en la Cámara de Diputados sobre la federalización de la enseñanza en México. A propuesta de José Vasconcelos la Cámara delibera sobre la conformación de una Secretanía de Educación Públicay el debate radica en si dicha Secretaría no atenta contra la autonomía de los Estados y su libertad de instrucción. Los argumentos a favor de la creación de dicha Secretańa consistieron en dar a los mexicanos auna educación homogénea y común que incluya la castellanización e inclusión a los valores de occidente» El criterio entonces no fue de autonomía, pluralismo y libertad sino la centralización de la educación a través de la Secretaría.

${ }^{27}$ RIVERO, Jean., «aïcité scolaire et signes dáppartenance reliquiense»,, Revue Francaisededroitadministratif., Paris., 1990. ${ }^{28}$ Este texto forma parte de una de las lecturas de nuestro libro Formación cívica y ética., reconocido por la SEP para $3^{\circ}$ de secundaria. ${ }^{29}$ Op.cit., p.713.

${ }^{30}$ Op.cit., p.719.

${ }^{31} \mathrm{~F}$. et R, 3. 
${ }^{32} \mathrm{~F}$. et R, 2.

${ }^{33} \mathrm{~F}$. etR, 1.

${ }^{34} \mathrm{~F}$. et R, 9.

${ }^{35} \mathrm{~F}$. et R, 10.

${ }^{36}$ Col. 1., Tm. 1, 17.

${ }^{37}$ Cfr. Ex. 33., II; Jn. 15, 14-15.

${ }^{38} \mathrm{I}, 12$.

${ }^{39} \mathrm{I}, 13$.

40 II, 19.

${ }^{41}$ II, 22.

42 II, 23.

43 II, 24.

44 II, 16.

${ }^{45}$ IV 36.

${ }^{46} \mathrm{IV}, 37$.

${ }^{47} \mathrm{IV}, 38$.

${ }^{48} \mathrm{IV}, 41$.

${ }^{49} \mathrm{IV}, 42$.

${ }^{50} \mathrm{IV}, 44$. 